\title{
Infectious diseases in humans and their prevention over time
}

\section{Las enfermedades infecciosas en el hombre y su prevención a lo largo del tiempo}

Rolando Neri-Vela*

Escuela Médico Naval, Mexico City, Mexico

Ailments caused by various microorganisms in humans have been a great problem in history; plague, smallpox, tuberculosis, measles, etc., have challenged human mind ingenuity for preventing human beings from them.

I will address only a sample of these illnesses.

Before the discovery of America by Christopher Columbus in 1492, bubonic plague, leprosy, smallpox, cholera and malaria, were unknown in America and, ever since, diseases have become cosmopolitan.

The plague has been referred in the Bible; around 1000 B.C., Hebrew exiles in Egypt, during the years that included the reign of Akhenaten (or Amenophis IV) (c. 1379 B.C.), had coined the expression "the ten plagues of Egypt" to describe the disasters caused by locusts, rats, floods, famine and disease.

We know that, since the Middle Ages, as soon as there was news that an epidemic was going to devastate a region, the population took shelter in their homes to avoid contagion, and the doctor who was to visit the house of some plagued person covered himself with his clothes from neck to ankles, wore gloves and a wide-brimmed hat, as well as a mask that at the level of the nose and mouth had a kind of beak, inside of which a cloth soaked in vinegar or some aromatic substance was placed in order to avoid breathing the miasmas caused by the disease. In addition, he wore glasses, with this outfit being a reminiscent of the clothing currently used by health personnel to attend the wards of patients affected by coronavirus disease 2019 (COVID-19).

Two variants of the plague are known, bubonic and pneumonic plague, and several outbreaks have been known throughout history.
Two physicians who worked independently to unravel its causative agent were Japanese doctor Shiba Saburo Kitasato, who was with Robert Koch in Berlin between 1886 and 1891, and Alexander Yersin, a Swiss disciple of Louis Pasteur and Émile Roux. While in Hong Kong during the 1894 plague, both discovered that the bacillus currently known as Yersinia pestis was present in the tissue of rats and humans killed by the plague. Two years later, in Bombay, Paul Lewis Simond discovered that the link between rats and man was the Xenopsylla cheopis flea; although other flea species can also transmit this disease, Xenopsylla cheopis is considered to be the main vector of the plague in its bubonic form.

Currently, with the timely use of antibiotics such as streptomycin and tetracycline, pneumonic plague mortality rate is practically zero, which is why the Haffkine and Ferran-Haffkine vaccines, which were created for its prevention, are already in disuse, since, currently, the cases of plague are fortunately rare.

Another disease that has wreaked havoc in humanity is tuberculosis, which was originally a disease of cattle and other mammals that secondarily spread to human beings. Since the domestication of animals in the Neolithic period, the arrival of bovine tuberculosis infection in humans may coincide with the phase of animal breeding. A center for cattle domestication in the northeastern Mediterranean basin occurred during the seventh to sixth millennium B.C. Milking of cattle probably occurred in the fifth millennium B.C. Propagation from infested cattle to humans was largely due to the ingestion of infected milk, and this could explain the predominance of bovine tuberculosis in children, and it should not be forgotten that it could also have 
been caused by ingestion of infected cattle meat. The earliest evidence of tuberculosis in animals is of Indian origin, since there is clear evidence of the disease in elephants before 2000 B.C., and in the Pleistocene, India elephants are known to have spread through Mesopotamia towards the limits of Asia Minor. ${ }^{2}$

Although tuberculosis has drastically decreased thanks to preventive medicine, it continues to be a threat with the emergence of human immunodeficiency virus and AIDS, poverty and the resulting mendicancy.

In 1882, Robert Koch discovered the bacillus that causes tuberculosis, and the vaccine created by Albert Calmette and Jean-Marie Camille Guérin in 1922 has saved many human lives, and prevented incapacitated beings as well.

I want to emphasize that the Spanish term for flu, gripe, comes from French (grippe), and means "claw" or "hook" due to the very symbolism the disease has when it captures us and causes certain symptoms. Influenza is Italian, and indicates the "influence" of external factors such as air and temperature.

A flu outbreak is likely to have affected the Greek army during the siege of Syracuse in 395 B.C., and influenza is thought to have been present throughout the West and Middle East during the Medieval period. The so-called English sweat of 1485 could have been a flu. The first unequivocal form of influenza over Europe dates from 1170, and later, in 1426-1427, it affected Spain, France, the Netherlands and the British Isles, and it is possible that the disease crossed the Atlantic Ocean in 1493 with the passengers of Christopher Columbus's second voyage to America, since after the docking of the ship, a great mortality occurred among natives. ${ }^{3}$

The so-called Russian flu developed in 1889-1890, and originated in Turkey, to then invade Russia, Finland and, shortly after, Europe, America and the rest of the world.

Owing to wars and their consequences, including poverty, hunger and overcrowding, typhus was a common disease, and Mexico was no exception. Several experiments had already been made to obtain a vaccine against typhus; in Germany, where, with limited success, in 1916 Hamdi used heated defibrinated blood taken from patients on typhus acute phase as a vaccine; and, around the same time, Charles Nicolle in Serbia used serum instead of blood. In 1930, Rudolf Weigl, in Poland, prepared a typhus vaccine based on rickettsiae experimental inoculation into lice, whose intestines and feces were ground and treated with formaldehyde, and despite the fact that it was used on a large scale and with good results, it had to be discontinued for being complicated to prepare and requiring 100 to 200 lice per dose.

With the same purpose of having a vaccine against typhus fever, Hans Zinsser, between 1937 and 1939, obtained a reasonable amount of rickettsiae after inoculating them into the peritoneal cavity of rats. This method was improved in Mexico by one of the best scientists the country has ever had, Maximiliano Ruiz Castañeda, by infecting the respiratory tract of rats. Another contribution of Ruiz Castañeda in the field of typhus, was to prepare and apply a divalent vaccine that included both Rickettsia prowaseki and Rickettsia typhi, the murine typhus agent, since, in those days, both agents were highly prevalent in Mexico and were responsible for a high number of cases. ${ }^{4}$

The 1918-1919 pandemic is known as the Spanish flu, despite the fact that it did not originate in Spain, but in the USA. Spain, which remained neutral in World War I, notified about its presence. The first outbreak was detected on March 4, 1918, in a US Army camp in Funston, Kansas, and travelled with the USA military contingent to France. On April 1, it appeared in the Gallic country, contaminating the civilian population and all contending forces. One month later, it was active in regions such as Spain, Portugal, Italy, Greece, Albania, Scotland, North Africa and the Balkan Peninsula.

The second wave of the Spanish flu came out of the cities of Brest (in France) and Boston (in the USA), as well as Freetown (in Sierra Leone), during August 1918. By the end of February 1919, Europe, North and South America, Africa and Asia were invaded, with the disease ceasing by the end of December. The last outbreak located in Europe and North America concluded in March. ${ }^{5}$

The first influenza virus in humans was isolated in 1933 by researchers Wilson Smith, Christopher Howard Andrewes and P.P. Laidlaw, from the National Institute for Medical Research in London, revealing that the strain that caused the Spanish flu pandemic was model A, H1-N1 subtype, of the Orthomyxovirus family. As of 1939 , the mortality rate from this disease began to decline thanks to sulfonamides and antibiotics therapeutic use, by slowing down the advance of bacterial pneumonia secondary to viral infection. ${ }^{6}$

In April 2009, in California and Texas (USA), and in the States of Oaxaca and Veracruz (in Mexico), the first cases of hospitalized patients with severe respiratory infections and high lethality were observed, 
which alerted the health authorities on the need to identify the cause, and it was until late April that reports were issued about a new influenza virus, AH1N1, which is why, later, the World Health Organization raised that warning to pandemic level 5, given that cases were detected all over the world. ${ }^{7}$

In 2003, severe acute respiratory syndrome (SARS) appeared, and by the end of 2019, COVID-19, which has been a devastating epidemic from the health and economic point of view, among other aspects; in 2020, some experts warned that half the world population would be infected by COVID-19 by the end of that year. ${ }^{8}$ Adding further difficulty to the fight against this pandemic, new strains have emerged, which are increasingly contagious and have affected all age groups.

The truth is that some governments have acted rather tepidly to confront the COVID-19 pandemic, or have ignored its potential lethality, exposing the population to its effects, which have been largely aggravated by the poverty and ignorance of people.

Several COVID-19 vaccines have already been developed, such as Pfizer, Astra-Zeneca, Moderna, Cansino, Sputnik and several others, which are being rapidly applied in many parts of the planet, but as long as authorities do not set a good example by using face masks and applying the "healthy distance" measures, and the population underestimates the importance of vaccination and does not believe in the existence of the severe acute respiratory syndrome coronavirus 2
(SARS-CoV-2), the fight against current epidemic will not have an end in the short term.

\section{Funding}

This research has not received any specific aid from public or commercial sector agencies or non-profit entities.

\section{Conflict of interests}

The author declares that he has no conflicts of interest.

\section{References}

1. Watts S. Epidemias y poder. Historia, enfermedad, imperialismo. BarceIona: Editorial Andrés Bello; 1997.

2. Roberts C, Manchester K. The archaeology of disease. Second edition. Cornell University Press; 1999. pp. 136-137.

3. Maradona Hidalgo JA. Historia de las enfermedades infecciosas. Oviedo, Spain: Universidad de Oviedo; 2010. pp. 97-106.

4. Escobar-Gutiérrez A. Historia de las vacunas y de las vacunaciones. In: Escobar-Gutiérrez A, Valdespino-Gómez JL, Sepúlveda-Amor J, editores. Vacunas ciencia y salud. Mexico: Secretaría de Salud; 1992. p. 21.

5. Sánchez-Fernández LV, Neri-Vela R. Las enfermedades epidémicas de Asturias. De la peste bubónica de 1598/1602 a la gripe de 1918/1919. Oviedo, Spain: Ilustre Colegio Oficial de Médicos de Asturias; 2019. pp. $155-158$.

6. Echeverri-Dávila B. La gripe española. La pandemia de 1918-1919. Centro de Investigaciones Sociológicas. Madrid, Spain: Siglo XX; 1993. pp. 12-34.

7. Frías-Salcedo JA. Crónicas de la epidemia de influenza AH1N1 en México. 2009-2010. Relato de lo aprendido... Rev Sanid Milit Mex. 2010;64:280-6.

8. Jones DS. History in a crisis-Lessons for COVID-19. N Eng J Med. 2020;382:1681-3. 